\title{
DISCURSO DE POSSE COMO PROFESSOR TITULAR DA FACULDADE DE DIREITO DA UNIVERSIDADE DE SÃO PAULO
}

\author{
José Eduardo Campos de Oliveira Faria \\ Professor Titular do Departamento de Filosofia e Teoria \\ Geral do Direito da Faculdade de Direito da \\ Universidade de São Paulo
}

\begin{abstract}
Meus caros estudantes,
Exma. Sra. Diretora,

Douta Congregação,
\end{abstract}

Minhas senhoras e meus senhores.

Toda solenidade de posse de um novo membro desta Congregação é sempre um rito de passagem que marca a chegada formal de um professor ao ápice da carreira acadêmica. Na história da Universidade, que surgiu condicionada pelo embate entre a fé e a razão, esse rito é a última etapa de um tenso e complexo processo de escolha e entronização do mais jovem ao círculo dos mestres mais experientes.

$\mathrm{Na}$ transição da Idade Média para o Renascimento, o objetivo desse processo de escolha e entronização era proteger as instituições de ensino contra intervenções externas, especialmente a tutela da Igreja, para assegurar um trabalho intelectual independente e imune ao dogma religioso e à tradição. Com o avanço do conhecimento racional e secular produzido por comunidades acadêmicas ciosas de sua independência e autonomia, aos poucos esse processo assumiu a forma de um mecanismo seletivo baseado no mérito e na autoridade intelectual.

Mas, como todo conhecimento também é sempre um instrumento de poder e controle social, ora reproduzindo e justificando um padrão de organização econômica, ora criticando suas estruturas para subvertê-lo e torná-lo mais justo, eqüitativo e participativo, esse processo seletivo jamais foi imune ao entrechoque de paradigmas, às concepções conflitantes de mundo e valores científicos.

$\mathrm{Na}$ dinâmica desse confronto, como a história revela, as heterodoxias desempenham um importante papel no destino tanto das instituições acadêmicas quanto da própria vida social. Elas viabilizam o avanço do conhecimento, questionando o saber ideológico acumulado, propiciando a crítica epistemológica das teorias prevalecentes e identificando suas contradições internas com relação aos fenômenos que pretendem organizar e compreender.

Ao pôr em xeque o senso comum teórico que assegura a reprodução dos valores e práticas dominantes, ao debruçar-se sobre os efeitos sociais do calado e do reprimido, ao modificar métodos e procedimentos convencionais da pesquisa, ao 
refletir sobre as condições para uma nova relação entre técnica jurídica e prática política, as heterodoxias também contribuem para abreviar os períodos de pouca criatividade, de indigência intelectual, de enorme pobreza científica e de quadros mentais estreitos, chamados pelo historiador francês Fernand Braudel de "prisões de longa duração"

As heterodoxias, no entanto, sempre têm seu preço. Se no passado ele era representado pelo risco da cicuta, da fogueira e da forca, hoje ele se expressa pelo risco da incompreensão. Acima de tudo, e principalmente no âmbito do Direito e do ensino jurídico, esse preço muitas vezes tem a forma do desprezo a toda e qualquer tentativa de desenvolver uma imaginação prospectiva capaz de nos habilitar a decifrar o sentido dos acontecimentos, a agir como atores transformadores e a pensar o futuro como História.

Como vários outros mestres, também passei por esse risco durante minha carreira acadêmica. E foi justamente por isso que aprendi que os ritos de passagem, como é o caso desta solenidade de posse, não devem se limitar apenas à manifestação de apreço aos colegas que, com generosidade, recebem um novo par. Esses ritos constituem, igualmente, ocasiões propícias a meditações e julgamentos, a avaliações do passado e a apresentação de inquietações relativas ao objetivo do labor docente, aos destinos da Universidade e ao próprio futuro da sociedade.

Não creio, portanto, afastar-me das mais nobres tradições das Arcadas ao apresentar, além dos sinceros agradecimentos àqueles que me estimularam chegar vitorioso a este momento e a esta tribuna, um pouco de reflexão sobre o trabalho acadêmico e as sucessivas rupturas bifurcações com que nos defrontamos diariamente, na sala de aula, na pesquisa e na vida universitária.

\section{Senhora Diretora, Douta Congregação, Meus caros alunos.}

Assumo a titularidade num momento bastante singular da História contemporânea, em que a economia transnacionalizada coloniza a política, asfixia o espaço público dos direitos civis e sociais e retira da cidadania atributos antes considerados inalienáveis; em que o mercado é concebido como instrumento privilegiado de regulação social, fragmentando identidades coletivas e levando a lógica racionalizadora e acumuladora do capital a desprezar a Justiça, a ética, a solidariedade e tudo o mais que não é quantificável e monetarizável; em que as instituições e os serviços públicos são convertidos em meros e cada vez mais rendosos negócios privados; e em que mecanismos asseguradores de coesão e integração já não conseguem neutralizar a explosão de tensões latentes em sociedades semi-periféricas, como a nossa.

No plano sócio-econômico, é uma sociedade profundamente marcada por dualismos, contradições e iniqüidades. No plano político, é uma sociedade historicamente estigmatizada por formas oligárquicas de dominação e apropriação predadora dos grupos melhor organizados e mais agressivos na disputa pelos bens e 
riquezas coletivas. No plano cultural e, principalmente, acadêmico, é uma sociedade cada vez mais submetida à inibição da crítica e da criatividade, como lembra Carlos Lessa ("A universidade e a pós-modernidade", Dados, 1999, v. 42) na medida em que as filiais dos conglomerados mundiais que aqui operam necessitam apenas e tão-somente de operadores acríticos e alienados, facilmente recicláveis e com baixos salários, ficando a produção do conhecimento concentrada e continuamente alargada nos países centrais. No plano jurídico, é uma sociedade caracterizada pelo descompasso entre a consagração formal das liberdades jurídicas e a ausência de condições materiais para que seus supostos beneficiários possam exercê-las de modo pleno e efetivo.

Assumo assim a titularidade num período explosivo e sombrio, em que os valores, as atitudes e as esperanças que conformaram o modo de ver o mundo e a consciência social de minha geração, a de 68 , encontram-se corroídos. É um período em que os padrões de solidariedade e sentido ético de Justiça, tão presentes no movimento estudantil de três décadas atrás, cedem lugar a uma existência social monodimensional, a uma pasteurização domesticadora de corações e mentes e ao aviltamento das condições de vida e cidadania, em nome de uma racionalidade econômica que, ao desafiar a ordem social estatal e abrir caminho para um abrangente processo de desconstitucionalização de liberdades e prerrogativas, põe em xeque o único poder capaz de dar eficácia e sentido prático à própria noção de Direito, mesmo em suas dimensões mais elementares.

Assumo a titularidade, portanto, numa era de contradições e paradoxos, em que crescimento econômico se torna sinônimo de empobrecimento social; em que avanços tecnológicos culminam em novas formas de dependência; em que o desemprego estrutural e a disseminação de uma insegurança generalizada estão abrindo caminho para o ressurgimento de formas difusas ou mesmo explícitas de fascismo; em que o esvaziamento da capacidade do Estado de estabelecer limites às formas de produção e à dinâmica de acumulação capitalistas, de distribuir renda por via fiscal, de implementar políticas públicas, de articular o desenvolvimento e até de controlar a própria moeda o impede de discriminar interesses particulares em nome do interesse coletivo, pervertendo deste modo a autonomia e o sentido do poder público. Uma era, enfim, em que a própria democracia vai perdendo todo seu potencial distributivo e sua capacidade transformadora.

\section{Senhora Diretora, Douta Congregação, Meus caros alunos.}

Nesse contexto cinzento e opressor, a Universidade pública brasileira, à qual agora pertenço como professor titular, hoje enfrenta pelo menos três grandes crises estruturais e conexas, à imagem das instituições congêneres européias (como afirma Boaventura Santos, "Da idéia de Universidade para uma Universidade de Idéias", in RCSS, Coimbra, n. 20). 
A primeira é uma crise de legitimidade. Subjacente à universalização dos padrões capitalistas de produção, troca e acumulação, esta crise se revela pelo descompasso entre os anseios dos segmentos menos favorecidos por mudanças radicais na organização social e uma produção acadêmica cada vez mais direcionada pelo critério de rentabilidade e comerciabilidade da produção científica. Ou seja, pelos pactos mefistofélicos de setores da comunidade científica com aqueles que, ao financiar seus projetos, também impõem prioridades e valores, mercadorizam o saber, patenteiam o conhecimento e privatizam o domínio da criação e difusão cultural, neutralizando assim tanto o espírito crítico e transformador da Universidade quanto a lógica subjacente à sua trajetória histórica, que enfatiza a apropriação coletiva do saber por meio de sua mais ampla disseminação.

A segunda crise é de hegemonia. Subjacente a uma iníqua distribuição de renda e ao acesso desigual aos bens e serviços públicos, esta crise se traduz pela incapacidade da Universidade de desempenhar funções técnicas e questionadoras, reprodutoras e transformadoras, no âmbito de uma sociedade malformada e deformada por três séculos de escravidão e em cujo âmbito as relações de poder hoje cada vez se caracterizam por atos de força, cujo único marco referencial acaba sendo o próprio confronto.

A terceira crise é de caráter basicamente organizacional e se traduz pela flagrante incapacidade da Universidade pública de se estruturar de modo mais leve e desburocratizado, com currículos flexíveis capazes de acompanhar a diferenciação progressiva das áreas de conhecimento e programas aptos a propiciar um atendimento particularizado das distintas clientelas discentes. O preço a ser pago, aqui, é a perda de sua centralidade na vida social e econômica para novos centros de reflexão e pesquisa, que se apropriam de suas funções docentes e investigativas na medida em que conseguem atender, de modo eficiente, às demandas para a gestão administrativa, política e econômica de sociedades cada vez mais complexas.

Além disso, essa crise organizacional também é evidenciada pela progressiva asfixia orçamentária que tem condenado a Universidade pública a um fim lento, gradual e indigno; pela crescente imposição de padrões de custo/benefício incompativeis com sua autonomia e sua responsabilidade social; e pelo estabelecimento de critérios de avaliação subordinados a discutíveis imperativos de produtividade, limitando assim seu papel de geração de novas idéias e valores e de expansão das fronteiras intelectuais e científicas.

Este tem sido o caminho trágico imposto à Universidade pública brasileira, após seis ou sete décadas de uma industrialização tardia e acelerada, cuja mobilidade social e cujas alterações geo-ocupacionais levaram os filhos dos migrantes e das classes médias emergentes a bater nas portas do ensino superior estatal e, cada vez mais, a vê-las fechadas.

A ditadura militar na época de minha formação acadêmica, que para muitos dos jovens aqui presentes talvez seja hoje apenas uma referência histórica, uma simples efeméride, levou a meritocracia e a excelência acadêmica a serem substituídas pela massificação do ensino superior; pela redução generalizada dos critérios de 
avaliação dos alunos; pela facilitação da outorga de diplomas como resposta às demandas do movimento estudantil por mais vagas na Universidade pública; e por um viés descaradamente profissionalizante, que só privilegia o conteúdo utilitário do conhecimento.

Hoje, a crise fiscal do Estado contamina a Universidade pública brasileira com o vírus de uma obsessão produtivista, que a impede de vencer o desafio da formação e requalificação dos segmentos menos favorecidos da sociedade. E que também a obriga viver sob uma tensão entre exigências de resultados concretos no curto prazo e as perspectivas de médio e longo prazo próprias das atividades científicas em pesquisa de ponta.

\section{Senhora Diretora, \\ Douta Congregação, \\ Meus caros alunos.}

Evidentemente, não há novidade nestas reflexões. Se as faço nesta solenidade, contudo, é porque sem elas não há como avaliar tanto o ensino jurídico quanto seu objetivo. Se é certo que o ensino jurídico não está dissociado do Direito Positivo, é igualmente correto que este, por sua vez, não pode ser examinado sem o ambiente econômico, político e cultural que o envolve. O desenvolvimento histórico, como têm ensinado muitos dos clássicos das ciências sociais desde o século XIX, a partir da contraposição teórica entre Dilthey e Hegel, entre Weber e Marx, não se dá apenas como base no fundamento das idéias, mas também e acima de tudo, a partir de práticas inovadoras, de forças materiais e de transformações sociais.

Mergulhado na ilusão da imobilidade e da segurança, o ensino jurídico desprezou esse ensinamento. Por isso, não soube enfrentar a crescente complexidade de seu mundo circundante. Como conseqüência, acabou sendo atropelado por uma institucionalidade nova e por uma normatividade inédita e pluralista, surgidas, ambas, à revelia de seus paradigmas teóricos e fora do alcance de seu domínio técnico.

Partindo da crença na continuidade de uma ordem jurídica estável nos seus fundamentos econômicos, sociais, políticos, ideológicos e éticos, integrada por normas coesas, pretensamente unívocas e imunes às contingências da história, o ensino jurídico brasileiro estruturou-se de modo autárquico, do mesmo modo como se revelou incapaz de se auto-perceber como manifestação cultural da sociedade.

Ao privilegiar o formalismo e o normativismo, perdeu-se em prolixidades e tecnicismos, deixando-se seduzir por uma retórica vazia, e minada pelo princípio da autoridade. Ao valorizar o aprendizado de um conhecimento técnico, porém fragmentado, levou a um processo de especialização que se assenta no isolamento de aspectos fundamentais dessa realidade, ignorando os demais. O bacharel por ele formado, conseqüentemente, talvez continue sendo um profissional necessário. No entanto, pelas limitações estruturais do ensino jurídico, tem sido ele ao longo do tempo um profissional realmente útil? 
Decorre dessas limitações a dificuldade hoje enfrentada pelo ensino jurídico para acompanhar as discussões sobre o sentido, o alcance e os perigos dos novos tipos de sociabilidade gerados pela crescente mercantilização das relações sociais; sobre o caráter cada vez mais difuso e opaco da produção de regras jurídicas; sobre o esvaziamento dos mecanismos de expressão da diferenciação social e das instâncias de mediação entre o setor público e a sociedade; sobre o futuro da própria democracia, enquanto estrutura institucional para a formação da vontade coletiva e definição de interesses gerais.

Decorre dai, igualmente, a perplexidade do ensino jurídico com o fenômeno da internacionalização do poder e subseqüente perda da centralidade e da exclusividade de estruturas jurídicas forjadas com base nos princípios da soberania e da legalidade; com a heterogeneidade de situações sociais que já não conseguem ser disciplinadas por técnicas e estruturas jurídicas tipificadoras, como códigos, leis especiais e até constituições; com a normatividade dos espaços infra-estatais surgida das necessidades dos setores sociais cujos interesses, expectativas e valores não encontram acolhida nas instituições jurídico-judiciais formais; com as formas negociais e as regras auto-produzidas por conglomerados empresariais, instituições financeiras e redes transnacionais de comercialização de bens e serviços; com a usurpação de prerrogativas dos Estados por organismos multilaterais, impondo seus mecanismos regulatórios e abrindo caminho para um processo de harmonização e unificação legislativas.

Por isso, com suas idealizações alienantes e sem qualquer relevância para o entendimento das contingências do mundo real, as faculdades de Direito vivem hoje um preocupante distanciamento da realidade - processo comparável apenas ao grau de isolamento alcançado pelo pensamento escolástico nos tempos medievais. E é esse perigoso fosso que leva os cursos juridicos, fechados em seu mundo imaginário, a uma percepção equivocada de seu ambiente, de seu currículo e do mercado de trabalho; à incapacidade de enfrentar o desafio de pensar o impensado; enfim, ao vazio intelectual como resposta às realidades emergentes e aos problemas sociais, políticos e morais delas resultantes.

\section{Senhora Diretora, Douta Congregação, Meus caros alunos.}

Se a situação do ensino jurídico é assim tão preocupante e se a Universidade pública parece estar sendo destituída de seu sentido histórico como instituição autônoma, crítica e reflexiva, uma solenidade de posse, como esta, também deve, sobretudo, marcar um compromisso com determinados valores. E, se hoje posso valer-me desta tribuna para reafirmá-los, é porque, ao longo de minha trajetória na Universidade de São Paulo, seja como aluno, seja como professor, alguns fatores foram fundamentais para que aqui pudesse chegar. 
Deles, destaco o fato de que as Arcadas já estavam em minha vida antes mesmo de nela ingressar, pois sou filho e sobrinho de antigos professores, constituindome no terceiro membro da família Faria a atingir esta honrosa cátedra a qual, por ironia do destino, é a mesma no passado ocupada por meu próprio pai. E destaco, igualmente, o fato de ter tido a sorte de pertencer a uma geração marcada pela contestação da hipocrisia e pela negação ainda que anárquica da ordem então estabelecida; uma geração que, despertada para a vida pela revolução cultural chinesa, pela primavera de Praga, pelo "cordobazo" pelo massacre dos universitários mexicanos, pelas barricadas de Paris e pela ocupação das Arcadas por três meses, foi, pela experiência, descobrindo que a verdade nunca esteve entre as virtudes políticas e que as mentiras sempre foram encaradas como instrumentos justificáveis nessa matéria.

Para os integrantes de minha geração que optaram pela carreira acadêmica, interpretando a seu modo a premissa socrática de que uma vida não questionadora não vale a pena ser vivida, lecionar tornou-se, acima de tudo, uma forma de tomar parte da vida pública; um modo de ocupar o espaço público; enfim, uma maneira de exercer a criatividade no debate sobre o destino de nossa comunidade e sobre os rumos de nossa sociedade, o que nos abre uma importante dimensão da experiência humana que, de outra forma, nos ficaria fechada.

Um antigo aluno desta escola, Antonio Cândido, costuma dizer que do Largo São Francisco sempre aflora um pugilo de jovens que se insere com destaque nas diferentes esferas da vida nacional. As dificuldades do presente não podem nos afastar dessa verdadeira tradição das Arcadas. Mantê-la acesa, alastrá-la e fazê-la reluzir é tarefa de todos os docentes, especialmente os de minha geração.

Destaco ainda, e agora como uma forma de evocação e reverência, a influência e o peso que dois mestres brilhantes tiveram na aprendizagem e na percepção do Direito por minha geração: o temido professor de Introdução, Alberto Muniz da Rocha Barros, sempre entreabrindo a interface do Direito com a Economia e distribuindo zeros aos magotes quando não se aprendia a lição, e o paraninfo de minha turma, José Ignácio Botelho de Mesquita.

Por fim, e permitam-me apenas mais duas observações pessoais, confesso que não teria chegado até aqui sem o estímulo generoso de amigos fraternais constituidos ao longo da vida, como José Carlos Dias, Flávio Bierrenbach, Olavo Setúbal, José Reinaldo Lima Lopes e Floriano Azevedo Marques, nem, muito menos, sem a interlocução e o diálogo intelectual com os quatro preceptores que a vida acadêmica generosamente me propiciou, como Boaventura Santos, da Universidade de Coimbra, como David Trubek, da University of Wisconsin, como Juan Ramón Capella, da Universitat de Barcelona e como Rolf Kuntz, do Departamento de Filosofia da Universidade de São Paulo, que me incorporou, aos dezoito anos de idade e primeiroanista desta escola, ao seminário fechado que o velho Frederico Heller, economista alemão fugido do nazismo e com enorme ascendência sobre seus colegas de profissão, realizava todos os sábados num canto acanhado da antiga sede do jornal O Estado de S. Paulo, na rua Major Quedinho, e ao qual compareciam, para conversas francas e por 
vezes rudes, empresários, políticos e os ministros que tanto execrávamos no movimento estudantil.

Dessa visão-de-mundo formada por experiências tão discrepantes e tão distantes do mundo singelo e simplista das salas de aula de meu tempo, é que moldei tanto minha trajetória acadêmica quanto meu relacionamento com sucessivas gerações discentes, das quais resultaram sólidas amizades e carreiras acadêmicas promissoras. $\mathrm{E}$ se àqueles quatro mestres seminais e queridos -Boaventura, Trubek, Capella e Kuntz sou eternamente devedor, a outros, que o convívio diário nestas Arcadas converteu em relacionamento fraternal, devo o apoio e o estímulo que jamais me faltaram para enfrentar os momentos mais difíceis e poder chegar a esta tribuna com altivez e dignidade, permitindo-me reafirmar, mais uma vez, meu compromisso com a formação humanistica e profissional de nossos alunos.

Esse apoio sincero e desprovido de quaisquer outras intenções que não sejam o respeito à ética, à meritocracia e ao que esta Casa tão tradicional tem de melhor, em seus quase 175 anos, permite-me terminar, mais uma vez agradecendo a todos, na pessoa da professora Odete Medauar, com suas palavras generosas, lembrando uma passagem de Fernando Pessoa:

"Pensar em nós o passado e o futuro,

Dorme em nós o presente. E a sonhar

A alma encontra sempre o mesmo muro,

E encontra o mesmo muro ao despertar"

Todas essas amizades, todos os aqui presentes, especialmente André, Murilo e Sandra - todos vocês, enfim, representam, para mim, o mesmo que o muro significa nos versos de Pessoa.

Muito obrigado.

São Paulo, abril de 2002. 


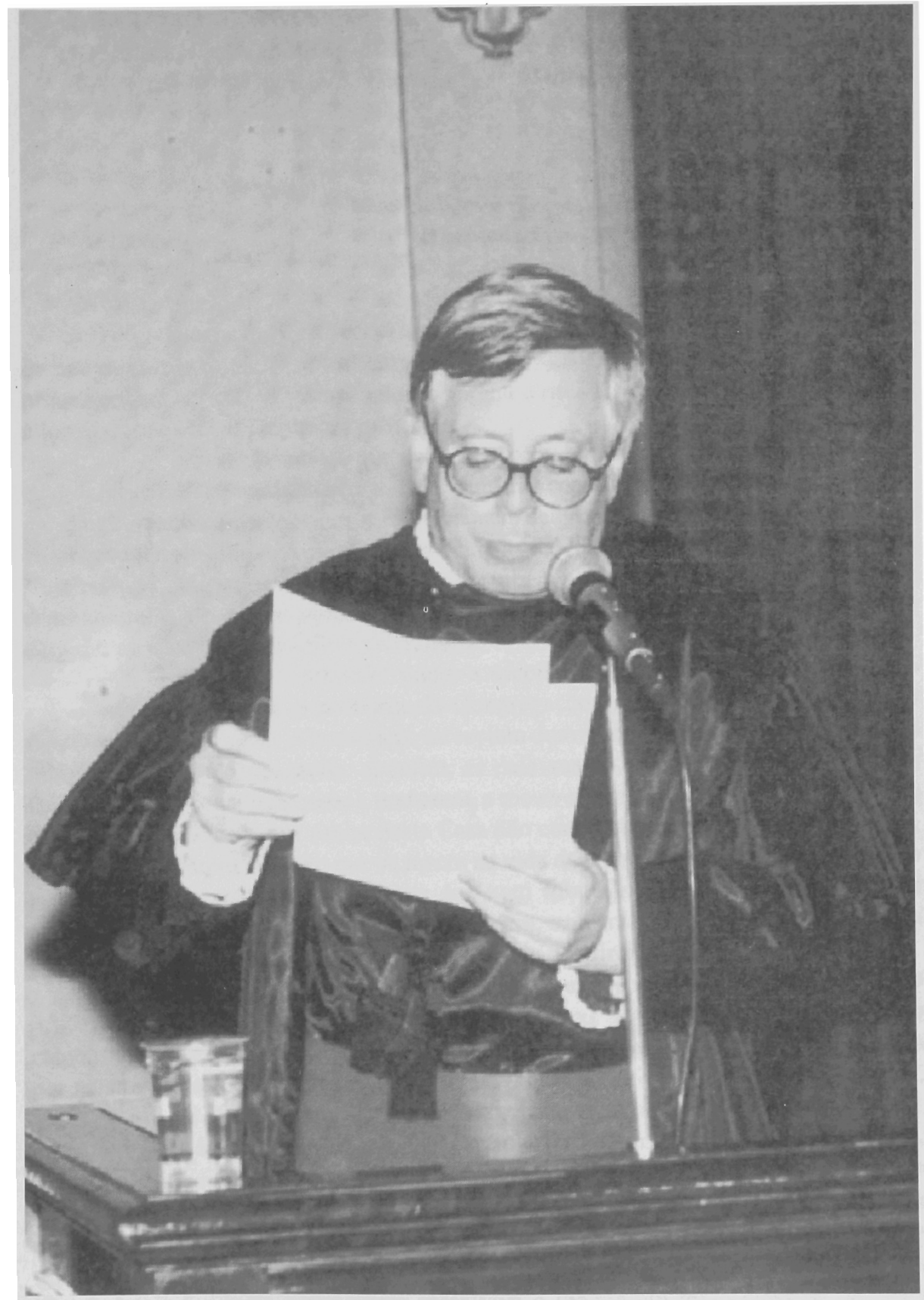

Professor Titular José Eduardo Campos de Oliveira Faria 